A qualitative analysis of the decoding error patterns among Filipino beginning readers transitioning to the Marungko approach

Bustos-Orosa, Maria Alicia $\square$

De La Salle University Manila, Philippines (maria.alicia.bustos-orosa@dlsu.edu.ph)

Ferrer, Maria Fe

De La Salle University Manila, Philippines (maria.fe.ferrer@dlsu.edu.ph)

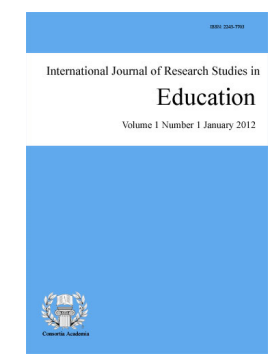

ISSN: $2243-7703$ Online ISSN: 2243-7711

OPEN ACCESS

\title{
Abstract
}

The current study focuses on the effects of previous exposure to a traditional reading approach in Filipino on the decoding proficiency of beginning readers in preschool introduced to the explicit phonics program called Marungko. Problems in reading Filipino words committed by five- and six-year old children in an outreach preschool within a low-income community are analyzed using decoding error pattern analysis. The results are attributed to the orthography of the Filipino language and the contextual variables that affect developing reading abilities among the sample group. The researchers conclude that during transitions from one reading approach to another, the unlearning of previously acquired letter-sound correspondences poses difficulties even in the mother tongue.

Keywords: decoding; mother tongue; Marungko; transparent orthography; qualitative 


\section{A qualitative analysis of the decoding error patterns among Filipino beginning readers transitioning to the Marungko approach}

\section{Introduction}

The development of literacy among preschoolers is an advocacy in Philippine education. To contribute to this objective, St. La Salle Preschool (SLSP) was established as an outreach preschool program of De La Salle University-Manila for children of low-income families living in the communities around the University. The school was established in 1997 and until 2008, the 5- and 6-year old children stayed for one year only before their entry into first grade. By 2009, St. La Salle Preschool introduced classes for 4-year old children, enabling the children to attend the school for two years before moving on to first grade in the public school system.

The school's medium of instruction is in the national language - Filipino, which is also the student's mother tongue. In 2009, changes in literacy instruction were introduced with the Marungko approach adopted as the explicit phonics instruction program. To date, the beginning reading program of the preschool uses both the Marungko approach and a literature-based approach using Filipino language storybooks for vocabulary development and comprehension. During the period of transition in 2009-2011, at which time the Marungko and literature-based reading program was introduced, teachers noted some difficulties students had in decoding Filipino words. It was also disconcerting that despite being their mother tongue, the students were having decoding difficulties in Filipino.

The initial observations of the difficulty some of the children experienced during the transition to Marungko were done during the initial implementation of the approach. The consequent two school years provided data consistent with the results of these initial observations.

\section{Literature}

\subsection{Review of Related Literature}

Researchers agree that in learning to read children use their knowledge of the sound structure of a language (phonological awareness or sensitivity), specifically, phonemic awareness- the ability to identify and manipulate individual sounds (phonemes) in words, and knowledge of the symbol-sound correspondences of a language (alphabetic principle) as factors in determining children's reading success (Adams, 1990; Ehri, 2001). The following sections review literature relevant to the study, the relationship of phonemic awareness and alphabetic knowledge to word reading development, phonics instruction programs and the Marungko approach.

\subsection{Phonemic Awareness and Alphabetic Knowledge in Word Reading Development}

Phonemic awareness is the awareness that speech is made up a sequence of sounds, specifically phonemes the smallest unit of sound in a language. Phonemic awareness also involves the ability to manipulate phonemes in spoken words. The awareness that speech is made up of a sequence of small units of sound is crucial for beginning readers of a transparent orthography language. In a transparent orthography, beginning readers can more easily draw the relationship between speech sounds to print at the phonemic level. The causal relationship between phonological awareness instruction and the improvement on children's spelling and reading achievement has been documented in numerous studies (Gray \& McCutchen, 2006, Ehri, et.al, 2001). The contribution of phonological awareness, specifically phonemic awareness, to children's reading abilities has mostly focused on word recognition (Gray \& McCutchen, 2006). Using their understanding of the grapheme-phoneme relationship is one of the strategies/skills children use to decode words in printed form. And 
A qualitative analysis of the decoding error patterns among Filipino beginning readers

it is the understanding of the grapheme-phoneme relationship that a large body of research concludes is the best predictor of children's early reading proficiency (Adams, 1990; Yoop \& Yoop, 2000; Ehri et al., 2001). Ehri (1998 in Morris et al., 2003) proposes four phases of word recognition in reading development. In each phase, Ehri explains how specific word bonds/features (letter-sounds, syllables, words) are encoded in memory through "experience, instruction, practice and repetition" (p. 144).

In the pre-alphabetic phase, there is no systematic letter-sound processing involved instead children rely on visual cues in the word. Children at this stage experience difficulties in word recognition when encountering words with similar visual cues in a text. As children learn to link spoken language with written text, they transition to the partial alphabetic phase. At this phase, some knowledge in letter-sound correspondences and skill in segmenting either the initial or final letter sound in words is necessary. Children learn to focus on the beginning and initial sound of words as cues for word recognition. As children gain more experiences and become more familiar with printed letters and sounds, they enter the full alphabetic phase. Children now use the learned strategy of the knowledge of letter sounds and blending to decode words. By processing each letter sound, they are better able to represent words in memory and read with more accuracy. The final phase, the consolidated alphabetic phase, children are able to identify multi-letter sequences common in words without attending to the individual letter-sound relationships. Reading then, becomes more efficient as children are able to break words into functional word recognition units (Morris et al., 2003; Harn, Stoolmiller, \& Chard, 2008). However, research also shows that some children who have not yet learned to read have difficulty in breaking down and analyzing spoken words into phonemes (Adams, 1990). Moustafa and Colon (1999) suggest a whole-to-parts phonics instruction program for these children who can and do analyze spoken words into larger units of speech, such as into onset and rimes and syllables.

\subsection{Phonics Instruction}

Phonics instruction programs that teach the phoneme together with letter identification have been more successful in building children's phonemic awareness skills especially in the blending and segmentation of phonemes which leads to successful decoding of written words (Ehri, 2001). Most reading programs include a phonics instruction component to teaching beginning decoding skills. In school, one of the first literacy lessons taught is the phoneme-grapheme relationship, such as the letter $\mathrm{m}$ says $/ \mathrm{m} /$. The phonics approach in any program is characterized by the manner in which children are taught to use their understanding and knowledge of the letter-sound correspondence to decode (read) words. Phonics instruction can be categorized either as an (1) explicit phonics approach or (2) as an implicit phonics approach (Stein, Johnson, \& Gutlohn, 1999). In an explicit phonics approach, letter sounds (phonemes) in association with its written form/symbol (grapheme) are taught in isolation. Children are then taught how to blend these together to form words. In this approach, the predominant word identification strategy is phonologically-based.

In an implicit phonics approach, letter sound identification is taught within the context of whole words rather than on the individual letters. Words identification strategies associated with implicit phonics are the use of context and picture clues in a text. Majority of reading programs employ an explicit systematic teaching of the alphabet and letter -sound relationships since research has shown that this has positive effects on early reading at the word level (Xue \& Meisels, 2004; Adams, 1990; Ehri, 2001). This is especially true for languages that have a transparent orthography or a consistent and regular correspondence between letter sound and symbol like Spanish and Filipino, the national language of the Philippines. In a review of reading methods in Spain, Goyen (1989) recommends that a systematic phonics approach should be an integral part of reading programs of languages with a regular orthography.

Traditionally, the phonics instruction program used in Philippine schools is the Cartilla Method. This method has its roots in the country's colonial past with Spain and in both languages having a regular orthography. The new Filipino alphabet is composed of the following 28 letter- sounds: a, b, c, d, e, f, g, h, i, j, k, 1, m, n, ñ, ng, o, p, $\mathrm{r}, \mathrm{s}, \mathrm{t}, \mathrm{u}, \mathrm{w}, \mathrm{x}, \mathrm{y}, \mathrm{z}$. Of these letters, 20 letters are from the traditional Filipino alphabet, called abakada, and 8 
letters are from the Spanish alphabet (c, f, j, n, q, v, x, z).

Spanish instruction in letter-sound correspondence has traditionally been syllabic (Moustafa \& Colon, 1999). The Cartilla method is based on this method of breaking down and analysing a word into syllables. Children are taught a set of syllables, based on the sequence of the consonants of the alphabet, that are then varied by one vowel (i.e., ba, be, bi, bo, bu). They are then taught to combine these syllables into words, (e.g. /ba/ /ta/ for bata, meaning child in Filipino) or to break up these syllable chunks in a printed word.

In recent years however, the Marungko Approach has been used as an alternative beginning reading program, in lieu of the Cartilla method, in most public schools in the Philippines. In the Marungko Approach, letter-sound correspondence is taught at the phonemic level. There is a specified sequence of letter and letter sounds to be taught to the children. The Marungko sequence is arranged according to the most frequent to the least occurring letters in the Filipino language. The sequence of letter-sounds taught in the Marungko approach is as follows: m, s, a, i, o, b, e, u, t, k, l, y, n, g, ng, p, r, d, h, w, c, f, j, ñ, q, v, x, z.

Unlike phonics instruction programs in English wherein vowels are introduced after the consonants, the Marungko Approach introduces vowels at the beginning of the sequence along with some consonants. For example, the sequence starts with the letters, $\mathrm{m}$, s, and a. Phonemic manipulation of blending letter sounds into words is introduced at this level. Children are then encouraged to make up words using these three (3) letters ("masa", "sama" etc). For instance, after teaching the letter sounds of m, s, a, i, o, b, e, u, students are asked to read the following words: ube (purple yam), ubo (cough), uso (modern), usa (deer). After reading words, students read phrases with words made up of these letters (e.g. ang ubas sa mesa, grapes on the table) the phrases for students' progress to sentences using letter combinations (e.g., May ubas si Ela. Ela has grapes.). Although Marungko is widely used at present in local schools, there has been no extensive literature related to this approach. This study in fact, contributes to the literature on this reading instructional program.

\subsection{Research Problem}

Based on the review of related literature, the researchers aimed to investigate the following research questions: What were the error patterns in decoding Filipino words manifested by preschoolers who had previous traditional reading instruction? What could account for these difficulties in reading in the mother tongue that may be attributed to changes in reading methods? Were these difficulties in transitioning to another beginning reading method related to the characteristics of the Filipino language? What contextual factors can account for successful transitions in beginning reading in Filipino from a traditional Cartilla method to the Marungko approach?

\section{Research method}

\subsection{Participants}

The children who were part of the study were all enrolled in the Prep Class of St. La Salle Preschool during June 2009 to March 2010 and from June 2011 to 2012. All the children were between the ages of five and six years at the time of study. These children come from families with a monthly income of P3,000 to P8,000. The minimum daily wage at the time of the study was at P350 per day. The children come from mostly single income families with the father working outside the home as construction workers, security guards, office workers, pedicab drivers and vendors. Mothers mostly stayed home to take care of the children.

The participants were taken from two groups of students. Group 1 consisted of the fifteen $(\mathrm{N}=15)$ children enrolled during the 2009-2010 school year and had no prior school experience. In Group 1, a total of 15 (n=15) students were included in the study. All 15 students had no prior school experience, and subsequently attended the preschool for only one year. 5 of the 15 (33.3\%) students had previous prior Cartilla instruction in the home.

Meanwhile, Group 2 consisted of the fifteen ( $N=15)$ five to six-year old children enrolled in the June 2011 to 
A qualitative analysis of the decoding error patterns among Filipino beginning readers

March 2012 school year. Of the 15 children in Group 2, only 5 children had prior Cartilla instruction at home. All the children except for two (2) were at their second year at the preschool. One of the two students had prior school experience and was exposed to the Cartilla method in their previous school. The $13(86.6 \%)$ children in Group 2 whose initial school experiences were at SLSP were taught the letter-sound relationship using the Marungko approach. However, 5 of the 15 (33.3\%) children were exposed to the Cartilla method at home. Some of them had older siblings in the public elementary school which still used the traditional method. The parents of these five (5) children were more familiar with the Cartilla method and used this to teach their children in the home.

\subsection{Data-gathering procedure}

Results of the study were gathered from the following data: Teachers' observations done throughout the school year and the summative reading assessment records obtained at the end of the school year. The summative reading assessment records were based on a Filipino word list. The word list was made up of Filipino sight words (ay, si, ang, $m g a$ ), words used in the daily class messages such as: days of the week, number names, color names; and words introduced in the context of literacy activities.

\subsection{Data analysis}

The summative reading assessment records were then analyzed qualitatively based on the corpus of reading errors committed during oral reading. The analysis of reading errors was initially conducted in previous studies on beginning reading (Cossu, Shankweiler, Liberman, \& Gugliotta, 1995; Fowler, Liberman, \& Shankweiler, 1977; Liberman \& Shankweiler, 1976). In these studies, the aim of the research was "to determine whether the errors made by beginning readers, when they attempt to read words and syllables, pattern consistently and if so, whether an analysis of their patterns of errors might provide insights into the problems of reading acquisition" (Liberman \& Shankweiler, 1976). Given previous literature using this research method, this study deemed that a qualitative analysis of the results would yield a more complete understanding of the phenomena.

\section{Results}

In Group 1, literacy knowledge upon school entry was limited to reciting the alphabet, and the recognition and identification of some letters and letter sounds. A third of the children in this group were taught letter-sound relationships using the Cartilla method in the home. In the course of Marungko instruction, of the 15 children, only $9(60 \%)$ were able to blend letter sounds to read words. Furthermore, for 7 out of the 9 children, these words were limited to the words taught in class or had the letters M, S, A, I, O, B-the initial letters in the Marungko sequence. When given a new word using the same letters that were not taught previously, the 7 children had difficulties blending as well. It seemed that the 7 children relied more on memorization of these words rather than on blending. Table 1 shows a sample of the decoding errors from Group 1.

\section{Table 1}

Sample Decoding Errors for Beginning Readers in Group 1 with Prior Cartilla Instruction

\begin{tabular}{l|l|l|l|l|l}
\hline \multicolumn{1}{c|}{ Stimulus Word } & \multicolumn{1}{|c|}{$\begin{array}{c}\text { English } \\
\text { Translation }\end{array}$} & \multicolumn{1}{|c}{ Student C } & \multicolumn{1}{|c}{ Student K } & \multicolumn{1}{c}{ Student S } & Student AK \\
\hline maasim & sour & ma-a-sima & ma-sa-bi & No errors & ma-a-sa-i-ma \\
\hline samba & go to church & si-m-bo & No errors & No errors & sa-i-maba \\
\hline masabi & said & ma-sa-i & ma-sa-i & No errors & ma-sa-ba-i \\
\hline bibo & precocious & i-o & ba-i-ba-o & boso & ba-i-ba-o \\
\hline bibisa & get better & i-i-sa & ba-ba-sa & No errors & ba-i-ba-i-sa \\
\hline
\end{tabular}

The following were also the observed difficulties the children exhibited in the transition from being taught to focus on syllables in decoding to text to focusing on letter-sound relationships at the phonemic level. At the level of phonological awareness, children had a tendency to include the short /a/ sound when asked to sound out a 
particular letter. For example, /M/ was sounded out as $/ \mathrm{ma} /$. Consequently, when decoding a word most consonants were sounded out with an /a/ sound. For example- the word pito (seven) was read as pa/i/to; and ako (me) was read as $/ \mathrm{a} / \mathrm{ka} / / \mathrm{o} /$, apat (four) as a/pa/a/ta. With time, some children were able to overcome this, but, would still add an /a/ sound to words that ended with a consonant (i.e., halaman read as halama/na/). In reading, words with a consonant chunk in the middle of the word, the sound of the letter /a/ or another vowel sound would be added, as in tatsulok (triangle), which would be read as ta/tas/ ulok or ta/tis/ ulok. Sample errors for Group 2 are provided in Table 2.

\section{Table 2}

Sample Decoding Error Patterns for Group 2 Beginning Readers with Prior Instruction in Cartilla

\begin{tabular}{|c|c|c|c|c|c|}
\hline \multirow{2}{*}{$\begin{array}{c}\text { Filipino } \\
\text { Word List }\end{array}$} & \multirow{2}{*}{$\begin{array}{c}\text { English } \\
\text { Translation }\end{array}$} & \multicolumn{4}{|c|}{ Sample Reading Errors } \\
\hline & & Child 1 & Child 2 & Child 3 & Child 4 \\
\hline anim & $\operatorname{six}$ & a-ni-i-m & ayam & ana-i-m & $\mathrm{am}$ \\
\hline ikaw & you & ika-a-wa & ikawa & ika-a-w & kawa \\
\hline bilog & round & ba-i-lo-ga & ba-i-log & ba-i-loga & biloga \\
\hline itim & black & i-ta-i-m & itayma & ita-ima & way-ta-mo \\
\hline okra & okra & o-ka-r-a & ora & oka-r-a & okara \\
\hline tatsulok & triangle & ta-a-ta-sa-u-1-oka & tas-uloko & taatasa-u-1-oka & sasaluka \\
\hline Miyerkules & wednesday & mi-wa-e-r-ka-u-l-esa & miya-eraka-ulesa & m-i-i-er-ka-u-1-i-s & mwa-ir-ka-yules \\
\hline parisukat & square & paa-r-isa-uka-ata & parisisukata & paar-i-s-u-ka-ata & pariwayukata \\
\hline eroplano & airplane & e-r-o-p-1-a-n-o & eropalano & i-er-p-pa-la-ana-o & ir-o-palano \\
\hline
\end{tabular}

It was also observed that when reading, children who relied on the cartilla method would count off with their fingers and chant the syllables as they read a word. For example, in reading simba, a child would chant sa-se-si while counting off with her fingers. Nonetheless, once a child seemed to have understood the letter-sound relationship, the /a/ sound was dropped. These children were then observed to decode words with more ease and automaticity.

In Group 2, consistent observations of children's decoding difficulties were also observed. It must be noted that Group 2 had two years of preschool experience in St. La Salle. Of the 15 students, 5 (33.3\%) children had a smooth transition to using the Marungko approach in learning to decode words, although these children initially started blending with a vowel sound at the end of consonants. The same transition difficulties observed in Group 1 were also evident in 10 out of the 15 (67\%) among the Group 2 children. However, all children in Group 2 $(\mathrm{N}=15)$ of the study were beginning readers at the end of the school year.

For both groups, these difficulties were: adding a short vowel /a/ sound after each consonant and rote recall of 'ba be bi bo bu' while counting their fingers to identify letter sounds in a stimulus word. However, in group 2 , 6 of the 10 children were able to overcome these difficulties and were observed to read words with more fluency. Furthermore, in Group 2, 4 of the 10 children who were observed to have had transitional difficulties were not able to overcome these problems by the end of the school year. They were still observed to add a short vowel sound after a consonant in blending letters sounds to decode words.

Meanwhile, there were two students (Child J and M), observed by the teaching staff who transitioned without much difficulty to Marungko observed by the teaching staff. Both students were observed to be highly interested in reading and being read to. They spent a lot of time with storybooks in school and would ask for teachers to help them read the words they see around the classroom or in a book. It is interesting to note that for these two children however, their exposure to print was mainly thru school given their lack of resources at home.

Child J and Child M developed an understanding of the one-to-one correspondence of phoneme-grapheme in doing blending activities in school especially with words without vowels beside consonants (e.g., simba, etc.) Once child $\mathrm{M}$ had acquired the phoneme-grapheme relationship, $\mathrm{M}$ no longer relied on chanting /ba/be/bi/bo/bu/ and was able to read with more automaticity. He was also read to at home more than the other children in the 
A qualitative analysis of the decoding error patterns among Filipino beginning readers

group. He also developed an understanding that there were two different strategies at play-Cartilla (which was not "allowed" in SLSP) and Marungko. Teachers also observed that the home environment could be a factor in Child $\mathrm{M}$ overcoming transition difficulties as his mother started teaching him using Marungko at home after a parent-teacher conference.

Child $\mathbf{J}$ had a more difficult transition despite being read to at home using Filipino storybooks (via the school's lending library) but the teaching via Cartilla was more consistent in the home. Despite overcoming the transition difficulties, she would still resort to the strategy of adding a vowel sound when encountering a consonant chunk in a word.

Based on the teacher's observations, the home environment may contribute to the ease or not in transition. Literacy activities in both reading and writing that involved a lot of phonemic blending may be another. Ehri (2005 in Morris, 2008) explains how in each phase of word development, experience, instruction, practice and repetition, specific word features in this case, letters-sounds are encoded in memory

\section{Discussion}

The findings of the current study raise several propositions as to why transition difficulties in decoding in the same language had been observed. First, attributions to the inherent characteristics of Filipino as a transparent orthography are first offered. Second, the role of phonemic awareness to reading fluency, or dysfluency in this case, is also pointed out in the discussion. Third, deficiencies in the environmental and contextual factors that limit access to phonological representations are also offered by the researchers. Lastly, the researchers surmise that such transition difficulties may also be explained by the limitations in working memory and flaws in phonological representations for letter-sound correspondences.

\subsection{Filipino as a Transparent Orthography}

Filipino as a spoken and written language shares a transparent orthographic system with Spanish where spelling indicates pronunciation of words (Cuetos \& Suarez-Coalla, 2008). Like Spanish, Filipino words are made up of short vowel sounds.

The "Spanish orthography is highly transparent, according to two criteria proposed by Seymour, Aro and Erskine (2003): high-spelling-sound predictability and very simple syllabic structure. In Spanish, mappings between graphemes and phonemes are consistent across all words" (cited in Cuetos \& Suarez-Coalla, 2009, p. 584). The Filipino orthography, similarly, meets these two criteria. For instance, vowel sounds do not require different pronunciations. Hence, when a child is taught the CV syllable /ma/ for the letter-sound /m/, a beginning reader will decode the words 'mama' and 'mana' in the same way.

Moreover, "with regard to syllabic structure, in Spanish it is very simple: the most common type of syllable is consonant-vowel (CV), most syllables are composed of only two or three letters, and there are few consonant clusters, all of which occur only at the beginning of the syllable" (Cuetos \& Suarez-Coalla, 2009, p. 584). Like Spanish, Filipino also abides by a very simple syllabic structure composed mostly of consonant-vowel syllables such as, 'ba-ta' ('child'), 'pi-to' ('seven'), or 'la-ro' ('play').

\subsection{The Marungko Approach and Letter-name Knowledge}

In the Marungko approach, beginners are specifically taught both the letter name and the corresponding phoneme. In this case, the letter name is taught as a letter sound as well (i.e., /b/ as /ba/). Cardoso-Martins, Resende, and Rodrigues (2002) state that "knowledge of the names of the letters plays an important role in reading acquisition" (p. 409). In the Marungko approach, although it is clearly accepted that letter-name knowledge should lead beginning readers to the sound-symbolizing function of letters, beginning readers learn that even the letter names are traditionally pronounced or read out as a syllable sound. 
In this study, although beginners are first formally taught Marungko when they enter formal schools, such teaching contradicts the traditional cartilla method where parents associate letter names with syllabic units (e.g., letter $\mathrm{t}$ as $/ \mathrm{ta} / / \mathrm{te} / / \mathrm{ti} / / \mathrm{to} / \mathrm{tu} /$ ). As deemed from the responses of the students in this study, there is an apparent recognition of similar letters (that all words begin with the same letter and are to be decoded beginning with the same phoneme). The difficulties arising during the transition from traditional cartilla to Marungko however, could be accounted for by the misrepresentation or connections made between letter names and syllabic sound correspondences.

Gray and McCutchen (2006) define phonological awareness for insights at the level of individual phonemes. "Children who are better able to identify sounds within words can more easily map letters onto those sounds and, thereby, benefit from the generative patterns inherent even in spelling systems that are not perfectly alphabetic, such as English" (Gray \& McCutchen, 2006, p. 325). Perhaps the interesting point of the data in this study is that the transition, even within one's language from one reading approach to another, poses difficulties for beginning readers.

\subsection{The Development of Phonemic Awareness and Transition Difficulties}

Most reading researchers do agree that "there is a reciprocal or interactive relationship between phoneme awareness and early reading skill" (Morris et al., 2003, p. 305). It is also widely accepted that phoneme awareness is manifested in varied developmental forms in beginning reading. There are two developmental models of phoneme awareness that may account for the results of this particular study - Frith (1985) and Ehri (1998).

Frith (1985, cited in Morris et al, 2003, p. 305) proposed a three-phase theory of reading acquisition, with each phase dominated by a specific type of reading strategy. According to Frith (1985) these phases are the logographic phase, alphabetic phase, and the orthographic phase. "In the logographic phase, children are able to recognize familiar words by attending to salient graphic features; however, they do not use phonology or letter sounds as a way to identify printed words. In the alphabetic phase, children 'sound out' new words they meet in print by attending to the sequential letters sounds in the words. In Frith's orthographic phase, children recognize new words instantly by attending to their distinctive orthographic or spelling patterns... According to Frith's three-phase model, phoneme awareness is absent in the logographic phase; it is central in the alphabetic phase (to decode sequential letters sounds, one must be aware that words are composed of sounds"; and it has outlived its developmental usefulness in the final orthographic stage" (Morris et al., 2003, p. 305).

Based on Frith's study, the sample group in this study may be within the alphabetic phase, as they sound out words sequentially. Nonetheless, Frith's (1985) theory fails to account for the unique finding in this study, wherein beginning readers though attending to letter-sounds sequentially, revert to syllabic psychological units than to individual phonemes.

Ehri (1998) subsequently proposed an alternative four-phase developmental reading theory, made up of: the pre-alphabetic, the partial alphabetic, full alphabetic and the consolidated alphabetic phases (Morris et al, 2003 , p. 305). In this theory, the "pre-alphabetic phase, similar to Frith's logographic phase, children remember how to read words by connecting salient visual cues in the word with the word's pronunciation and meaning. There is no systematic letter-sound processing in this stage" (Morris et al, 2003).

In the partial alphabetic phase (Ehri, 1998), "beginners commit printed words to memory by forming connections between one or more letters in a printed word and the corresponding sound(s) detected in the word's pronunciation... To enter this partial alphabetic phase, children must know some letter-sound correspondences and be able to segment either the initial and final sounds in words" (Morris et al., 2003, p. 305).

In this study, beginning readers possess letter-sound correspondences and seem able to segment initial, medial and final sounds in its correct sequence. For this, the readers seemingly belong to the partial alphabetic 
phase based on the theory of Ehri (1995). However, beginners tend to revert to syllabic correspondences for individual phonemes in a word and have difficulties progressing to blending letter sequences effectively. Hence, there is a seemingly immature or underdeveloped and inefficient retrieval of letter-sound correspondence.

"Researchers agree that proficient readers use their knowledge of language, their knowledge of letter-sound correspondences, and their background knowledge to read (i.e., make sense of) alphabetic writing. The areas in which there is disagreement is the question of how children who are learning to read an alphabetic script become proficient, independent readers" (Moustafa \& Maldonado-Cohen, 1999).

In the English language, beginning readers can and do analyze spoken English into onsets and rimes. Onsets are consonants before a vowel in a syllable, while rimes are the vowel and any consonant after it in a syllable. For instance, English beginning readers can analyze the word smiles as /sm/ and /ilz/ even without identifying its individual phonemes as /s/, /m/, /i/, /1/, and /z/. (Moustafa \& Maldonado-Cohen, 1999, 449).

Like Spanish, Filipino is not an onset-rime language. "That is, Spanish syllables do not divide naturally between a syllable-initial consonant and the following vowel. The psychological units of spoken Spanish words are syllables" (Moustafa \& Maldonado-Cohen, 1999, p. 450).

"With regard to syllable structure, in Spanish it is very simple: the most common type of syllable is consonant-vowel (CV), most syllables are composed of only two or three letters, and there are few consonant clusters, all of which occur only at the beginning of the syllable” (Cuetos \& Suarez-Coalla, 2009, p. 584).

As had been pointed out previously, the traditional instruction of Filipino as similar to Spanish in letter-sound correspondences, has been syllabic, that is teachers teach children sets of syllables that vary by one vowel such as ba, be, bi, bo, bu.

"Because the psychological unit of spoken Spanish is the syllable, we assume that Spanish speaking children make analogies at the syllabic level. That is, by learning to recognize the print words cocio and comio, children figure out that co- is pronounced $/ \mathrm{ko} /$, and then they use that knowledge to pronounce co- in other words they encounter with co- (Moustafa \& Maldonado-Cohen, 1999, p. 450).

"Previous research on children's use of analogies to pronounce unfamiliar print also tells us that children's knowledge of analogous print words better accounts for their ability to pronounce unfamiliar print words than their knowledge of letter-phoneme correspondences" (Moustafa, 1995 cited in Moustafa \& Maldonado-Cohen, 1999, p. 450). However, given the lack of emphasis on reading print words in the traditional cartilla method, beginning readers rely on familiar syllable-based letter-phoneme correspondences instead. Based on this previous finding, it may be inferred that the beginning readers in this study, may have made analogies in the letter-sound correspondence of the stimulus print words with the psychological units of syllables rather than individual phonemes, as with the Spanish samples.

Adams (1994) proposed the vulnerabilities of the phonological processor that may partially explain the difficulties in decoding among the readers in this study. According to Adams (1994), "the phonological processor takes letters or multi-letter patterns as input from the orthographic processor. It responds with any and all pronunciations that it has associated to that letter or spelling pattern. The speed and strength of its response(s) depend on three factors: the instantaneity and quality of the orthographic information it receives; the number of different responses that the orthographic input elicits; and the familiarity of the appropriate response" (p. 167).

Based on the aforementioned assumption, it may be possible that the transition difficulties experienced by beginning readers may also be due to the over dependence of the phonological processor on the orthographic unit. Hence, for poor decoders, an individual letter or grapheme may elicit all pertinent phonemic units, including unwarranted phonemic units.

Adams (1994) states further that if letters arrive one by one from the orthographic processor, "the first letter 
perceived will evoke all of its various phonemic translations, and each of these phonemic units will relay excitation to all others with which it has become associated... In general, visual letter recognition failures do not result in no response- as many as the perceived aspects of the letter evokes. In these cases, the Phonological processor not only missed the preemptive activation of the correct letter but must also cope with the misguided activation from all of the alternative candidates" (p. 168).

In the current study, the results may be attributed to the beginning reader's over-reliance on all the phonemic translations that a single phoneme evokes (i.e., when decoding the ending consonant, there is a tendency to add /a/ as in halaman to 'halama-na'). Similarly, when beginning readers begin decoding, they resort to recalling from rote all the consonant-vowel syllables linked to a single phoneme (i.e., b as ba, be, bi, bo, bu then choosing which shares the same orthography).

Adams (1994) also writes that "it is not the general frequency with which a word occurs in print but the frequency with which it has occurred in the experience of the person reading it. It is after all, one's personal experience with a word or spelling pattern that determines the strengths of the associations it evokes" (p. 170).

In the context of the current study, the beginning readers had very limited print exposure before formal schooling. Among low-income families, it is generally accepted that children are not provided with literacy-rich environments. The probability that a child has previously or repeatedly been exposed to a word or spelling pattern in its printed form, is very unlikely under these circumstances. In most cases, where the parents are either illiterate or have poor reading skills, children will not be afforded optimal opportunities to encounter print. In other words, the beginning readers in this study may not have the prior knowledge or experience to determine appropriate letter-sound associations from previously encountered words or spelling patterns.

\subsection{Cognitive Variables related to Transition difficulties}

Given the partial attribution to phonemic awareness and developmental reading theories proposed in accounting for the current study's results, the researchers surmise that such transitional difficulties may possibly also arise from related cognitive variables, specifically retrieval or phonological representations from memory.

Wolf et al. (1998, cited in Hester \& Hodson, 2004) state that "mental representations at the phonological level comprise codes for the individual sounds of a language and rules for ordering and combining them" (p. 115). In this study, it is hypothesized that beginners form schemas for individual sounds in its syllabic form initially. When the Marungko system is then introduced, beginners must deconstruct such schema to adapt to a grapheme-phoneme- specific schema.

Baddeley et al. (1984) likewise stress "the nature of phonological representations as important because it comprises the basic code that must be retrieved from long term memory and held in working memory while a message is decoded" (cited in Hester \& Hodson, 2004, p. 117). "Working memory functions as a system for temporarily holding and manipulating information during performance of a range of cognitive tasks" (Baddeley, 1986 cited in Hester \& Hodson, 2004, p. 117).

Hester and Hodson (2004) propose as well that "sometimes what appear to be memory problems in reality are reflections of flaws in the stored phonological representations and in the organization of this information" (p. 117). It may be possible that the results of this particular study reflect such flaws in stored phonological representations given the repeated exposure to syllabic letter-sound correspondences. These flawed phonological representations, in turn, impede fluency in decoding sequential phonemes.

Hester and Hodson (2004) also state that "in Kindergarten and 1st grade, children become formally acquainted with the alphabetic principle, the concept that the letters of the alphabet stand for speech segments or phonemes. With reading and other linguistic experience, phonological and associated orthographic representations typically become firmly established" (p. 117). Moreover, "to use reading efficiently as a tool, 
A qualitative analysis of the decoding error patterns among Filipino beginning readers

children must have an explicit level of phonological awareness, which should be evident in performance on tasks such as sound manipulation" (Hester \& Hodson, 2004, p. 117).

These aforementioned assumptions by Hester \& Hodson (2004) when related to this study's findings, may point to the flawed representations acquired for letter-sound correspondences during the partial alphabetic phase (Ehri et al., 2001). It may also be partially explained by the difficulties encountered by poor vs. good readers. The reduced phonological interference experienced by poor readers was interpreted by Mann et al. (1980) as evidence that poor readers do not use phonological representations in short term memory to the same extent as good readers (Cited in Gray \& McCutchen, 2006).

In Hester \& Hodson (2004), the study of Stackhouse (1997) is also cited where phonological awareness is presumed to develop along a continuum from tacit to explicit awareness. "In the tacit end, analysis includes syllable segmentation and rhyming, while sound segmentation and manipulation reflect explicit levels of word analysis" (Stackhouse, 1997, cited in Hester \& Hodson, 2004, p. 116). Stackhouse (1997) further concluded that the child who is a successful decoder must therefore have adequate orthographic experience to support this level of phonological awareness. Consistent with the hypotheses relating to the phonological processor's dependence on previous experience and repeated exposure, the beginning readers in this study had limited orthographic experiences due to environmental and familial conditions.

\section{Conclusion}

The initial data on beginning readers of Filipino Tagalog who were transitioning from the traditional Cartilla approach to the Marungko approach put forward the unique experience of encountering difficulties in decoding in the same language given two albeit conflicting reading instruction approaches. The apparent lack of difficulties in decoding among children who had no prior instruction in the traditional Cartilla approach supports a focus on direct instruction in letter-sound correspondence through a systematic explicit approach, embodied in the Marungko approach.

As formal instruction in Marungko typically begins with four-year olds, some students already have prior reading instruction in the home. Therefore, it is highly suggested that parent education in beginning reading instruction among low-income families should be implemented. Even more, given the lack of print exposure among low-income schoolchildren, it is imperative that provisions for literacy materials and access to print be given in these communities.

Given the limitations of this qualitative research, a mixed-methods research to documenting students' decoding difficulties in a similar setting is highly recommended. The conduct of such research would certainly shed light on the experiences of preschool children in literacy instruction.

\section{References:}

Adams, M. J. (1994). Beginning to read: Thinking and learning about print. Massachusetts: MIT Press.

Cardoso-Martins, C., Resende, S., \& Rodrigues, L. (2002). Letter name knowledge and the ability to learn to read by processing letter-phoneme relations in words: Evidence from Brazilian-Portuguese-speaking children. Reading and Writing: An Interdisciplinary Journal, 15, 409-432. http://dx.doi.org/10.1023/A:1015213514722

Cossu, G., Shankweiler, D., Liberman, Y., \& Gugliotta, M. (1995). Visual and phonological determinants of misreadings in a transparent orthography. Reading and Writing: An Interdisciplinary Journal, 7 , 237-256. http://dx.doi.org/10.1007/BF02539523

Cuetos, F., \& Suarez-Coalla, P. (2009). From grapheme to word in reading acquisition in Spanish. Applied Psycholinguistics, 30, 583-601. http://dx.doi.org/10.1017/S0142716409990038

Ehri, L., Nunes, S., Willows, D., Schuster, B., Yaghoub-Zadeh, A., \& Shanahan, T. (2001). Phonemic awareness instruction helps children learn to read: Evidence from the national reading panel's meta-analysis. 
Reading Research Quarterly, 36(3), 250-287. http://dx.doi.org/10.1598/RRQ.36.3.2

Fowler, C., Liberman, I., \& Shankweiler, D. (1977). On interpreting the error pattern in beginning reading. Language and Speech, 20, 162-173.

Goyen, J. (1989). Reading methods in Spain: The effect of a regular orthography. The Reading Teacher, 42(6), 370-373.

Gray, A., \& McCutchen, D. (2006). Young readers' use of phonological information: Phonological awareness, memory and comprehension. Journal of Learning Disabilities, 39(4), 325-333. http://dx.doi.org/10.1177/00222194060390040601

Harn, B., Stoolmiller, M., \& Chard, D. (2008). Measuring the dimensions of alphabetic principle on the reading development of first graders: The role of automaticity and unitization. Journal of Learning Disabilities, 41(2), 143-157. http://dx.doi.org/10.1177/0022219407313585

Helman, L. (2004). Building on the sound system of Spanish: Insight from the alphabetic spellings of English-language learners. The Reading Teacher, 57(5), 452-460.

Hester, E., \& Hodson, B. (2004). The role of phonological representation in decoding skills of young readers. Child Language Teaching and Therapy, 20(2), 115-133. http://dx.doi.org/10.1191/0265659004ct266oa

Liberman, I., \& Shankweiler, D. (1976, May). Speech, the alphabet, and teaching to read. Paper presented at the Conference on the Theory and Practice of Early Reading Instruction, Learning Research and Development Center, University of Pittsburgh.

Morris, D., Bloodgood, J., Lomax, R., \& Perney, J. (2003). Developmental steps in learning to read: A longitudinal study in kindergarten and first grade. Reading Research Quarterly, 38(3), 302-328. http://dx.doi.org/10.1598/RRQ.38.3.1

Moustafa, M., \& Maldonado-Colon, E. (1999). Whole-to-parts phonics instruction: Building on what children know to help them know more. The Reading Teacher, 52(5), 448-456.

Stein, M., Johnson, B., \& Gutlohn, L. (1999). Analyzing beginning reading programs: The relationships between decoding instruction and text. Remedial and Special Education, 20(5), 275-287. http://dx.doi.org/10.1177/074193259902000503

Xue, Y., \& Meisels, S.J. (2004). Early literacy and instruction in learning in kindergarten: Evidence from the early childhood longitudinal study: Kindergarten class of 1998-1999. American Educational Research Journal, 41(1), 191-229. http://dx.doi.org/10.3102/00028312041001191

Yoop, H. K., \& Yoop, R. K. (2000). Supporting phonemic awareness development in the classroom. The Reading Teacher, 54,130-143. http://dx.doi.org/10.1598/RT.54.2.2 